\title{
Building stakeholder engagement in sustainable solutions: the strategic advisory panel on selenium management
}

\author{
S. Swanson Swanson Environmental Strategies Ltd, Canada \\ R. Abbott Abbott Strategies, Canada \\ W. Funk WorleyParsons Canada Ltd, Canada \\ L. Kirk Enviromin Inc., USA \\ G. McKenna BGC Engineering Inc., Canada \\ H. Ohlendorf $\mathrm{CH} 2 \mathrm{M}$ Hill, USA \\ T. Sandy CH2M Hill, USA
}

\begin{abstract}
The Strategic Advisory Panel on Selenium Management is a broadly-based group of experts who have achieved success via independent, transparent stakeholder engagement with full collaboration across diverse disciplines. The Panel was formed in January 2010 to assist Teck Coal and its stakeholders in finding a sustainable approach to the management of selenium released from Teck's metallurgical coal mines in south-eastern BC and north-western Alberta. The Panel's Charter stipulated that the Panel would operate independently and would release a strategic plan for the management of selenium within six months. While part of the Panel's work was highly technical, an equally important activity was active engagement with stakeholders. Selenium is a controversial topic with significant technical uncertainties, and often with strongly held views by potentially affected people (concerning their health or effects on ecosystem services). Past attempts to deal with these uncertainties had not succeeded in producing an acceptable plan for managing selenium loadings to the watershed, which were steadily increasing. Trust among stakeholders was low. The Panel used one-on-one meetings, workshops, site visits, and community meetings to reach out to Teck personnel, regulators, First Nations, NGOs, elected officials, and representatives of key stakeholder groups such as fly fishers. The Panel's engagement activities, combined with the release of the strategic plan report without prior review by stakeholders (including Teck) produced a substantial increase in trust and engagement. The rapid acceptance of the report by the CEO of Teck Coal added to that trust. The involvement of stakeholders has continued into the implementation phase, which includes management of selenium at legacy waste dumps, incorporation of new operating procedures at active mines, inclusion of alternative mine and waste management practices for proposed expansions and new mines, and Teck's continued engagement with a community-based watershed-health advocacy group. The continued engagement of stakeholders is an integral part of Teck's commitment to sustainable mining. The Panel's experience shows that independent advisory panels can be an effective catalyst for trust-building, especially if their activities truly are governed by sustainability principles.
\end{abstract}

\section{Introduction}

The mining of metallurgical coal creates large volumes of waste rock which, when exposed to water and air, accelerate the release of selenium into the environment. The metallurgical coal operations of Teck Resources (Teck) in the Elk River watershed of south-eastern British Columbia and the McLeod River watershed near Hinton in north-west Alberta have contributed to increasing surface water concentrations of selenium. These concentrations exceed water quality guidelines for the protection of aquatic life (Dessouki and Ryan, 2010, Casey, 2005), and have also approached or exceeded the drinking water quality guideline at monitoring stations near Sparwood (Dessouki and Ryan, 2010). Furthermore, analysis by SRK Consulting has shown that the selenium concentrations are increasing in almost direct proportion to the volume of waste rock (SRK Consulting, 2008; Golder Associates, unpublished data). 
Teck identified the increasing trend in selenium concentrations as a significant business risk and sought to increase its understanding of selenium fate, transport and to identify solutions that might arrest the increasing trend in surface water concentrations. However, as of the beginning of 2010, the company had not been able to demonstrate that it had identified proven, sustainable management methods to address the selenium issue. This created business risk because Teck must receive permits for several upcoming mine expansions and mine re-openings to continue operations.

The Strategic Advisory Panel on Selenium Management (the Panel) was commissioned by Teck in January 2010 to create a strategic plan for the sustainable management of selenium at its six mines. The seven Panel members represented the fields of reclamation engineering, microbial geochemistry, toxicology, ecological and human health risk assessment, water and wastewater treatment, ecological economics, and sustainable development.

The Panel knew from the onset that not only did it have to deal with a wide range of technical issues, but that stakeholder engagement would be a key to its success.

\section{The panel charter}

\subsection{The importance of a charter}

The Panel believed that a formal Charter was important because of the low level of trust among Teck, regulators and stakeholders. The lack of trust was inherited by Teck after its 2008 purchase of the coal operations in the Elk Valley and at Cardinal River. Many years of difficult relationships among industry and stakeholders, as well as the lack of any progress in successfully reducing selenium loadings to the aquatic environment had combined to build a high level of cynicism and distrust.

\subsection{The basis of the panel charter}

The Panel developed a formal Charter in accordance with guidance in support of the U.S. Federal Advisory Committees Act (U.S. GSA, 2010), as well as recommendations provided by the Union of Concerned Scientists (2010), the US Government Accountability Office (U.S. GAO, 2009), and the Natural Resources Defence Council (NRDC, 2009). Canadian government guidance regarding advisory panels was not available, except for guidance related to scientific peer review of assessments of contaminated sites in the province of British Columbia. The Panel's activities went well beyond peer review.

The Charter's framework and rules of operation were designed to produce properly balanced, objective, unfettered opinion, free of any conflict of interest (SAPSM, 2010a). All Panel members were required to sign a conflict of interest disclosure document that identified any past financial relationships with Teck. Obviously, Panel members could not consult directly with Teck while serving on the Panel. If a Panel member's organisation had patented proprietary technology and/or tools that were included in Panel recommendations, the Panel member was required to declare a conflict of interest during consideration of the technology or tool and recuse themselves from Panel discussions involving any recommendation relating to that technology or tool.

\subsection{Demonstration of panel independence}

The Panel recognised the inherent contradiction between being commissioned and paid for by Teck and the provision of independent advice. Therefore, the Charter went into some detail regarding the maintenance of Panel independence.

The most important measure taken to demonstrate the independence of the Panel was the release of the Panel's strategic plan for selenium management simultaneously to all stakeholders, including Teck. Teck had no opportunity to review the strategic plan report prior to its release. Teck showed courage in agreeing to this stipulation in the Panel Charter; this courage was duly noted by stakeholders and was a substantial factor in contributing to an increase in trust in the Panel process and in Teck's commitment to the management of selenium.

The Panel communicated independently with regulators and stakeholders. Teck and stakeholders were copied on materials to be presented as well as minutes of such meetings; however, Teck did not have 
authority to change or edit those materials, except when factual errors regarding Teck operations were identified.

\section{Fast-track to a plan for the sustainable management of selenium}

The Panel's primary objective for the first half of 2010 was to develop a strategic management plan for selenium that integrated the environmental, social and business opportunities and risks associated with selenium management. The deadline was June 30, 2010.

Producing a strategic plan within six months for a subject as complex as selenium management was a daunting task. The Panel decided to divide itself into two sub-groups, a technical sub-group and a stakeholder engagement sub-group. The technical sub-group focussed on assembling, interpreting and integrating the substantial body of scientific work on the fate, transport and effects of selenium as well as the engineering knowledge of how to manage legacy, current and future rock dumps to reduce or eliminate selenium release to the aquatic environment. The stakeholder engagement sub-group focussed on reaching out to a broad range of stakeholders, gathering data on stakeholder issues, and using a variety of approaches to re-build trust. Both the technical and stakeholder engagement sub-groups worked within a sustainability framework.

\subsection{Translating sustainability to real-world action}

Sustainability is a roadmap for human development that integrates environmental, social and economic wellbeing. The Panel used the following definition of sustainability:

“... a process in which the creation of financial and social wealth and wellbeing does not reduce the aesthetic and productive capacity of natural capital available for present and future generations" (Abbott, 2008).

Several important concepts are embedded in this definition. The first is the reference to sustainability being a process rather than a utopian end state. The second is the explicit reference to the creation of both financial and social wealth. The third is the requirement that financial and social capital creation not be at the expense, either productively or aesthetically, of natural capital. Finally, this definition requires that the productive and aesthetic capacity of natural capital be maintained for future generations. The Panel used this definition to guide its work (SAPSM, 2010b).

Teck's vision of sustainability is:

"While the scope of our activities may evolve, our mission is to find, extract and provide natural resources to society for the benefit of present and future generations - "Resource Stewardship for Generations". With this in mind, we work to identify the material ways in which our activities may impact sustainability and develop the strategies that will guide us as we maximise opportunities and minimise our impacts". (Teck, 2008).

The management of selenium is, in many respects, an object lesson in the implementation of sustainability "on the ground" because it tests the extent to which Teck has created a culture that truly considers "people, the environment and communities of interest, now and in the future, with every decision" (SAPSM, 2010b). The Panel observed that this was not happening consistently at Teck's coal operations. For example, mine planning (for ore production and waste rock management) did not incorporate selenium management as a key objective and performance metric, despite the fact that selenium had been identified as a key business risk.

The challenge faced by the Panel was to develop a selenium management strategy that built upon the sustainability commitments made by Teck but that achieved a higher level of integration of all of the parts of the selenium issue. These parts included scientific and technical knowledge, community values, and economic imperatives.

\subsection{The initial situation with stakeholders}

There were many strongly-held views among stakeholders and a history of firmly entrenched positions with respect to the nature and size of the selenium problem. Past attempts to deal with the scientific uncertainties 
included Teck-commissioned research, university research and government reviews. Advisory panels had also been formed and had operated for several years. All of these efforts produced useful and applicable science, but did not produce consensus on an acceptable plan for selenium management.

The Panel observed that there were several causes of the failure to achieve consensus around selenium management. There was a fundamental difference in risk tolerance among stakeholders. Some stakeholders did not accept any exceedance of selenium water quality guidelines. Other stakeholders (Teck included) insisted on the use of population-level risk thresholds for selenium concentrations that were substantially higher than current or proposed water quality guidelines. Uncertainty around the science used to generate effects thresholds added to the debate, as did the lack of any acknowledgement of different value systems. Scientific and technical uncertainty played a key role in delaying any action on selenium management. Understandably, Teck was unwilling to implement costly technology when it didn't know what the target for selenium would be. Regulators were inclined to use the precautionary principle when confronted with scientific debate about risk thresholds. The precautionary principle leads to target selenium concentrations that would be almost impossible to achieve (and would almost certainly not be sustainable).

While decisions were deferred, selenium loadings continued to increase in direct proportion to the volume of waste rock. Patience was running thin among stakeholders, and Teck's social license to operate (and to grow) was eroding.

\subsection{Stakeholder engagement in development of the strategic plan}

\subsubsection{The panel's approach to initial engagement with stakeholders}

A stakeholder map was an early priority, resulting in the identification of the key, high-impact, highinfluence stakeholders who became the focus of subsequent Panel engagement efforts. Mapping identified elected officials, Teck employees, provincial and federal regulators, First Nations representatives, members of NGOs, local government employees, local business owners (including tourism and recreation), and local leaders in education and environmental awareness.

An internal risk assessment exercise within Teck confirmed that selenium had a high risk rank. It also revealed the interactions among economic, social and environmental aspects of the selenium issue. The size of the effort required to manage the issue had major business and social implications, both negative and positive.

Engagement with the key stakeholders began with informal one-on-one discussions that proved to be vital because many of the key stakeholders were sceptical and often somewhat apprehensive about what they would experience should they agree to attend multi-stakeholder meetings. Often, more than one informal meeting was necessary before individuals were sufficiently comfortable with the Panel's process that they would agree to further participation.

In order to ensure a consistent approach was used for each of the informal meetings, the Panel developed a standard series of open-ended questions that were asked of each stakeholder. Questions were organised according to five themes: Panel operations; stakeholder profile; selenium as a chemical of concern; management of selenium; and socio-economic issues. The answers to the standard protocol questions were used as the primary method for gauging initial stakeholder opinions and attitudes.

The standard protocol questions yielded useful baseline information. Most stakeholders were satisfied with the independence and objectivity of the Panel and expressed particular satisfaction about the provision in the Panel Charter for release of the strategic plan for selenium management without prior review by Teck. Several stakeholders stated that it would have been preferable for Teck to have been more transparent regarding its intent to form a Panel and then with its process for the selection of Panel members. Advice to the Panel focussed on frequent interaction with stakeholders and commitment to follow-up. The most frequently-stated concerns about selenium were related to the continuous increase in concentrations, generating questions about human health and safety, effects on aquatic life, and effects on the quality of life of area residents. Cumulative effects were raised by many stakeholders, as were concerns about effects on valuable components of the economy such as fly-fishing. The importance of Teck to the local economy was emphasised repeatedly. This was especially true for the Elk Valley in British Columbia, where local 
governments reported that Teck accounted for a substantial portion of the tax base $(77 \%$ in the case of Elkford, 57\% in the case of Sparwood).

The primary message with respect to management of selenium was that "it is time to get on with it". There was no patience for further research or monitoring without action on reducing selenium loadings at the watershed level. There was a general call for Teck "to do the right thing".

\subsubsection{Achieving stakeholder engagement in development of the selenium management plan}

\section{Stakeholder workshops}

Once the Panel had established rapport and trust (albeit cautious trust) among the key stakeholders, two workshops were convened, one in Fernie, British Columbia, and one in Hinton, Alberta. The workshop agendas were developed to explore stakeholder perceptions and attitudes toward sustainability and the selenium management challenge, and to craft an objective for selenium management that reflected broad stakeholder interests.

The objective statements that emerged from each workshop captured the essence of sustainability. These objectives were adopted by the Panel. The objectives are presented below.

\section{Fernie Stakeholder Workshop Objective Statement for Selenium:}

"Define, implement, monitor and communicate sustainable ways to stabilise and reverse the selenium trend in the Elk River water shed as soon as possible. 'Sustainable' implies the context of continued mining and growth as well as social and environmental values."

\section{Hinton Stakeholder Workshop Objective Statement for Selenium:}

"To manage selenium at current and future Teck Coal mine sites in a way that optimises the mitigation of environmental impacts, protects critical ecosystem goods and services, allows for the continued extraction of the resource, and ensures ongoing community and social well-being for generations in Yellowhead County."

Specific actions in support of this objective are:

1. Decrease the loading to the receiving environment and establish a decreasing trend within three years.

2. Subsequent to item 1, manage selenium to a target that provides a sufficient margin of safety for humans, fish and aquatic life and wildlife.

3. Pioneer the use of selenium management practices that benefit the community both during and following mine life by positioning the community as a knowledge centre on selenium.

4. Engage Yellowhead County residents, and others who benefit from the assets of the County, in an ongoing dialogue about (1) selenium (so as not to cause alarm); (2) management actions; (3) progress; and (4) anticipated next steps.

The mixture of technical experts and lay people at the workshops produced innovative ideas for selenium management that may not have been identified if a narrower group of people had been consulted. A lively discussion yielded 45 different options.

The workshop discussion of criteria to use for evaluation of options helped ensure that the Panel's analysis of the options was inclusive and thorough. Examples of criteria suggested by stakeholders and adopted by the Panel included aquatic ecosystem health, percent disturbed area, degree of selenium reduction, timeline to demonstrate selenium reduction, quality of life index, and potential future liability.

The selenium management option identification and evaluation criteria produced by the workshops were used by the Panel for a multiple criteria decision analysis (MCDA). The results of the MCDA conducted by the Panel produced rankings for ten selenium management options selected by the Panel from the longer list suggested by stakeholders. The reaction of stakeholders to the MCDA analysis is reported in Section 4. 


\section{Site visits}

Tours of two of Teck's operations in the Elk Valley as well as the Cardinal River operation in Alberta were essential to the Panel's understanding of the selenium issue because they provided vital context regarding the history, geography, geology, and biology of the mine areas. The tours also provided the opportunity for the Panel to speak directly with Teck staff and mine management.

\subsubsection{Putting it all together}

By the time the Panel was ready to write its report, it had received the benefit of wide-ranging stakeholder engagement. Input from stakeholders contributed directly to the strategic plan and served as a complement to the detailed technical analysis performed by the technical sub-group of the Panel. The deeper understanding of what stakeholders would define as sustainable management of selenium helped the Panel as it strove to produce a strategic plan that was faithful to the Panel's definition of sustainability.

\section{$4 \quad$ Reaction to the release of the panel's strategic plan report}

The true extent of stakeholder engagement and trust could only become apparent after the release of the Panel's strategic plan report. The first indication was the rapid adoption by the CEO of Teck Coal, Boyd Payne, of the Panel report on July 15, 2010 (two weeks after release of the Panel report).

The reaction to Teck's adoption of the Panel report was very positive. Stakeholders who had historically been highly sceptical of Teck and its intentions regarding selenium management expressed gratification, tempered with questions about Teck's capacity for rapid implementation.

Meanwhile, the Panel was receiving direct feedback from stakeholders. The Panel met with Teck to respond to questions about the report, and to provide additional information and context for the Panel's recommendations. The Panel convened one-on-one and small group meetings with British Columbia and Alberta regulators and with community-based stakeholders. In all cases, the tone of these meetings was positive; while everyone wanted to see improvement, there was a commonly held view that selenium management will take time, and will require contributions from all stakeholders.

The responses indicated that trust in the Panel, the Panel's process, and in Teck had increased significantly within six months. Of course, there were still concerns expressed, related largely to the Panel's (and Teck's) commitment to continuing engagement into the implementation phase. However, the overall reaction was positive, hopeful, and engaged.

The MCDA conducted by the Panel received generally favourable reviews, particularly for its transparency. Some stakeholders devoted considerable time and effort to a detailed review of how the ten selenium management options were scored against the evaluation criteria by the Panel. These stakeholders reported satisfaction at their ability to check the ranking of each option and consider whether they would have agreed with the Panel's scoring.

\section{$5 \quad$ Engagement during the early stages of implementation}

The true effectiveness of a strategic plan is measured by the degree of implementation. Since the release of the Panel's report, Teck has assembled a dedicated team to develop and implement its selenium management plan. Some large capital projects are already underway. Permitting plans are undergoing significant revision in order to incorporate additional selenium management measures. Monitoring and research and development programs are being substantially revised and expanded. Communication with regulators is occurring at much more frequent intervals and Teck is working cooperatively with the Panel on continuing stakeholder engagement. All of this is encouraging and indicates a genuine commitment by Teck to the implementation of a sustainable selenium management strategy.

There were two competing pressures on the Panel regarding its role in the implementation phase; one was for the Panel to become much more deeply involved in technical aspects; the other was for the Panel to focus on stakeholder engagement. The Panel continued its engagement with stakeholders during the first months of implementation by conducting meetings with regulators, individual stakeholders and Teck staff. Meanwhile, two members of the Panel resigned in order to allow them to work directly with Teck as technical 
consultants. The remaining members continued to consider what would constitute the most useful and productive role for the Panel as it approached the end of its mandate in December 2010.

Teck made the decision in September 2010 to extend the Panel's mandate to the end of 2011. This decision was welcomed by stakeholders. The Panel decided to focus on three items: (1) stakeholder engagement; (2) the production of an Addendum to the Panel report; and (3) strategic advice and support.

Stakeholder engagement by the Panel continued with two community meetings held in October 2010 in Hinton and Fernie. Common themes that emerged from these meetings were effective communication, understanding risk tolerance from both a regulator and industry standpoint, accountability, dealing with uncertainty, and the need to re-vamp monitoring and research. Another primary theme was the need to view selenium management from a watershed perspective and not just one mine operation at a time. Engagement in Fernie was demonstrated by the willingness of stakeholders from Teck, regulatory agencies, First Nations and community groups to participate in a "Communication Action Team" that would serve as a vehicle for continuing communication and engagement.

The Panel's Addendum was released in May 2011 (SAPSM 2011). The Addendum's contents included an overview of Teck's progress in implementation, clarifications and corrections related to the Panel's original report, and new recommendations - this time aimed not only at Teck but at regulators and other stakeholders. The new recommendations reflected the Panel's opinion that a "step change" was required not only within Teck but also within regulatory agencies and the public if a truly sustainable selenium management program was to be implemented.

Workshops held in May 2011 in Fernie and Hinton confirmed that the increased level of trust first apparent in 2010 continued to exist, particularly in the Elk Valley. There are challenges in the Hinton area, primarily related to significant differences in risk tolerance as well as a greater level of apathy that may be due to the comparatively low profile of coal mining in Alberta.

One of the most encouraging developments among stakeholders is the formation of the Elk River Alliance (ERA), a multi-stakeholder group dedicated to "a new era in watershed thinking". The ERA is broadly supported by NGOs, government agencies and Teck. Its goals include increased access to information about water, public participation to restore and enhance aquatic ecosystems, and increasing water literacy. The ERA is one of the keys to continuing engagement in selenium management in the Elk River watershed and is one of the clearest indications of the significant increase in trust, rapport, and common purpose among stakeholders interested in the Elk River watershed.

\section{Conclusions and lessons learned}

The experience of the Panel has shown that expert advisory panels can be effective agents for change, not only with respect to technical and scientific actions but also with respect to stakeholder engagement. Thanks to the willingness of Teck and stakeholders to turn a new page, the Panel was able to lead a process that produced a step change in attitude as well as the beginnings of new structures and processes, both within Teck and among stakeholders. Challenges remain, particularly with respect to the resources required to maintain momentum. In addition, structure and process change is difficult - and changes often require years and substantial political will to accomplish. However, the Panel believes that a foundation has been laid that can lead to a long-term, sustainable program of selenium management that is watershed-scale and that involves fully engaged stakeholders.

The primary lessons learned are:

1. Panel independence is vital and should be formally established, documented and communicated.

2. It takes a significant level of courage for industry to commit to a truly independent advisory panel, but the results can be well worth it in terms of increased trust and social licence.

3. Panel members should be from a broad cross-section of expertise, including social sciences.

4. Panel deliverables should be well-defined and produced within as short a time period as possible.

5. Terms of reference for panels must include consideration of "what will happen next" after release of milestone panel reports. 
6. Panel involvement with stakeholder engagement can be a very effective approach to increasing trust.

7. Panels can assist in identifying the need for step change and assisting in achieving step change via strategic-level advice and continuing involvement in stakeholder engagement.

\section{References}

Abbott, R.M. (2008) Uncommon Cents: Thoreau and the Nature of Business. Green Frigate Books, Winnipeg, MB, Canada.

Casey, R. (2005) Results of Aquatic Studies in the McLeod and Upper Smoky River Systems. Alberta Environment. Available on-line: http://www.environment.gov.ab.ca/info/library/7743.pdf

Dessouki, T.C.E. and Ryan, A. (2010) Water Quality Assessment of the Kootenay, Elk and St. Mary Rivers. Prepared for B.C. Ministry of Environment and Environment Canada. Available on-line: http://a100.gov.bc.ca/pub/eirs/

Golder Associates Ltd. Unpublished Data. Selenium concentrations in water in the Elk Valley downstream of Teck Coal operations.

NRDC (2009) In response to the March 9, 2009 Presidential Memo on Scientific Integrity: Request for Public Comment. Natural Resources Defence Council Submission. Federal Register, Volume 74, No.77. Available online: http://docs.nrdc.org/health/files/hea_09051401a.pdf

SAPSM (2010a) Panel Charter. Strategic Advisory Panel on Selenium Management. Available from the Chair of the Panel. stella@ swansonenviro.ca.

SAPSM (2010b) The Way Forward: A Strategic Plan for the Management of Selenium at Teck Coal Operations. Strategic Advisory Panel on Selenium Management. Strategic Advisory Panel on Selenium Management. Available on-line: http://www.teck.com/Generic.aspx?PAGE=Teck Site/Responsibility Pages/Sustainability Pages/Environment Pages/

SAPSM (2011) Continuing the Journey: Toward Sustainable Management of Selenium at Teck Coal Operations. Strategic Advisory Panel on Selenium Management. Available from the Chair of the Panel. stella@swansonenviro.ca.

SRK Consulting (2008) Selenium Geochemistry and Water Quality Predictions Phase 1 Data Knowledge/Gap Review. SRK Project 1CE003.001. November 2008.

Teck (2008) Sustainability Report. Volume Two. Available on-line: http://www.teck.com/Generic.aspx?PAGE=Teck+Site\%2fResponsibility+Pages\%2fSustainability+Pages\%2fRe port + Archive\&portalName $=$ tc

U.S. GAO (2009) Scientific Integrity. EPA's Efforts to Enhance the Credibility and Transparency of Its Scientific Processes. Statement of John B. Stephenson, Director Natural Resources and Environment. GAO-09-773T. Available on-line: http://www.gao.gov/new.items/d09773t.pdf

U.S. GSA (2010) Preparing Federal Advisory Committee Charters. U.S. General Services Administration. GSA Office of Government-wide Policy, Office of Policy Initiatives. Available on-line: http://www.gsa.gov/portal/category/21243

Union of Concerned Scientists (2010) Ensuring the Independence of Scientific Advisory Committees. Available online: http://www.ucsusa.org/scientific_integrity/solutions/big_picture_solutions/scientific-advisorycommittees.html 